\title{
A novel method of sewage sludge pre-treatment - HTC
}

\author{
Małgorzata Wilk ${ }^{1, a}$ \\ ${ }^{1}$ Faculty of Metals Engineering and Industrial Computer Science, AGH University of Science and Technology, \\ Al. Mickiewicza 30, 30-059 Krakow, Poland
}

\begin{abstract}
The aim of the paper is to present a relatively new technology - hydrothermal carbonization (HTC) of municipal sewage sludge. The HTC process was conducted in a stainless steel, Zipperclave Stirred Reactor, with a volume of $1000 \mathrm{ml}$, equipped with a MagneDrive Agitator. The control panel provides a programme which regulates the heater temperature and mixer speed. The main parameters of the process were temperature $\left(\sim 200^{\circ} \mathrm{C}\right)$, pressure $(\sim 1.5 \mathrm{MPa})$ and residence time $(4,7,10$, and $12 \mathrm{~h})$. In order to understand the process, the physical, chemical, thermal, and structural characteristics of the solid product, hydrochar, was investigated. Therefore, the ultimate and proximate analyses, and HHV for raw material and obtained hydrochar are presented. The majority of carbon, of the initial present carbon, remained within hydrochar. TA analysis was used to detect the initial and final temperature for the combustion of raw material and hydrochar. This technique is very useful for predicting the combustion characteristics of carbonaceous material. When considering the use of hydrochar as a solid fuel, more energy can be derived from hydrochar than from e.g. incineration of waste, and its carbon emission should be less signific ant. Therefore, HTC can be an environmentally beneficial technique for the combustion process.
\end{abstract}

\section{Introduction}

In recent years, the rapid population growth, urbanization and industrialization have caused a significant increase in the amount of sewage sludge. Therefore, the development of new utilization methods of sewage sludge is an urgent problem which needs to be solved [1-3]. The most common disposal of sewage sludge is landfilling, farming applications and incineration. Sewage sludge can be treated as a potential energy resource despite containing a high level of pollutants. Nowadays, European and Polish legislation concerning sewage sludge treatment has become very restrictive in imposing the rapid development of thermal methods of sewage sludge utilisation (Figure 1). There are several thermal technologies for utilising municipal sewage sludge to obtain useful forms of energy through the correct pretreatment. One promising option is the hydrothermal carbonization process, which is an effective way to densify the energy content of sewage sludge without the prior drying process.

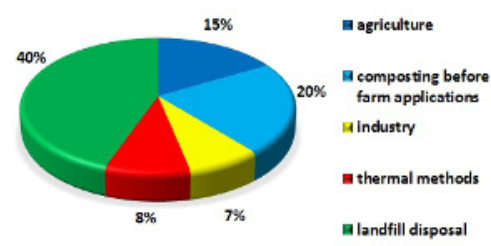

Figure 1. Sewage sludge disposal in Poland 2014, Central Statistical Office of Poland.

\footnotetext{
a Corresponding author: mwilk@agh.edu.pl
}

Hydrothermal carbonization (HTC) is a thermochemical process which involves the application of heat and pressure to convert raw material in the presence of water into carbonaceous biofuel. The HTC process results in three types of products: gases, aqueous chemicals, and a solid hydrochar. The gas product is about $1-3 \%$ of the raw material, consisting mainly of $\mathrm{CO}_{2}$. The aqueous extractive compounds can easily be filtered from the reaction solution, avoiding complicated drying schemes and costly isolation procedures. They are primarily inorganic salts, sugars, and organic acids. Hydrochar is a homogenized, carbon rich, and energy-dense solid fuel, biologically sterilized due to thermal treatment. The mechanisms of hydrothermal carbonization are associated with a series of hydrolysis, condensation, decarboxylation, and dehydration reactions. Reaction temperatures are applied within a range of $180-230^{\circ} \mathrm{C}$ and the various pressures are maintained above the saturation pressure to ensure the liquid state of water.

The HTC method has usually been used for a wide range of biomass feedstocks [4-11], where the effect of temperature, residence (carbonization) time, and carbonization yields have been studied. In the case of sewage sludge, the hydrothermal carbonization process was not so widely investigated, but studies were largely focused on the properties of solid product, energy recovery rate, hydrochar yields and its combustion characteristic, and improved dewaterability of sludge. The effects of hydrothermal carbonization were evaluated by varying the temperature and time [12-19]. In fact, regarding Polish 
conditions, there are no published results concerning the HTC of sewage sludge so far, that is why this technology can be named a novel pre-treatment method.

The major objectives of this research are to present the laboratory tests for HTC method of municipal sewage sludge pre-treatment. Therefore, the characterisation of the sewage sludge before and after the hydrothermal carbonization process is presented and the chemical changes after HTC pre-treatment are discussed. The TG/DTG/DSC results are also given to analyse the combustion behaviour and thermal characteristic of hydrochars.

\section{Materials and methods}

\subsection{Materials}

Dewatered sewage sludge was collected from the municipal wastewater plant in Gliwice, Poland. Sewage sludge with a moisture content of $85 \%$ was stored at $4^{\circ} \mathrm{C}$ and later used in HTC experiments. Part of the material was dried at room temperature for several days, resulting in $10 \%$ of moisture. It was then ground into a fine powder and kept in a sealed plastic container. An image of the sewage sludge is presented in Figure 2. Later, both the proximate and ultimate analyses of the sewage sludge were performed (Table 1).

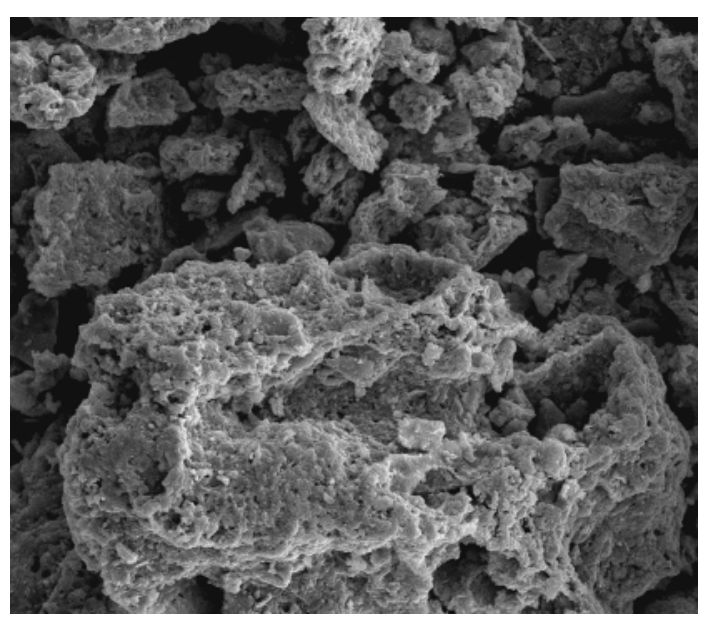

Figure 2. An image of the sewage sludge.

\subsection{HTC experiments}

HTC of the sewage sludge was carried out in a stainless steel, Zipperclave Stirred Reactor, with a volume of 1000 $\mathrm{ml}$, and equipped with a MagneDrive Agitator (Parker Autoclave Engineers). The Zipperclave is equipped with a low pressure spring closure, which is designed to reduce the time required to open and close the pressure vessel. The reactor is designed to work up to a maximum working pressure of $15.1 \mathrm{MPa}$ and a temperature of $232^{\circ} \mathrm{C}$. The magnet zone is capable of cooling down during the operating time, because a temperature in excess of $149^{\circ} \mathrm{C}$ could cause permanent damage, resulting in lost torque capability. Therefore, a stainless steel cooling jacket is provided between the drive connection and magnet zone to maintain the temperature in the magnet zone at $149^{\circ} \mathrm{C}$. The control panel provides a programme which regulates the heater temperature and mixer speed. The main seal and safety pressure release is made of teflon, an elastomer material. A schematic of the HTC apparatus is shown in Figure 3.

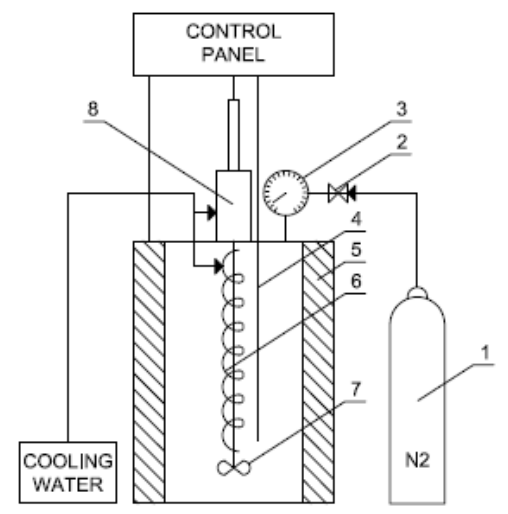

1-nitrogen cylinder, 2-valve, 3-pressure gauge, 4-thermocouple, 5-electrical furnace, 6-cooling coil, 7-stirrer, 8-cooling jacket.

Figure 3. The HTC apparatus.

In this study, $200 \mathrm{~g}$ of dewatered SS was dispersed in $300 \mathrm{ml}$ of de-ionized water and placed into the vessel. The mixer was stirred continuously at $150 \mathrm{rpm}$ to ensure the uniformity of reaction temperature in the samples. Then, nitrogen with a purity of $99.99 \%$ was supplied from the cylinder to the reactor in order to create an oxygen free atmosphere. The reactor was sealed and heated up to $200^{\circ} \mathrm{C}$ in an electric furnace. When this temperature was reached, four carbonizations times $4,7,10$, and $12 \mathrm{~h}$ were maintained. The pressure stabilized at $1.5 \mathrm{MPa}$. At the end of the carbonization time, the heater was turned off and the reactor was taken from the furnace and cooled down by water via a cooling coil. When the pressure and temperature decreased to room temperature, the reactor was opened to collect the remaining products. The mixture of solid and liquid products was firstly extracted from the vessel and placed in a graduated cylinder to observe the sedimentation time. Then, the solid product was separated from the liquid phase by using a vacuum filtration apparatus through microfiltration filter paper and oven dried at $105^{\circ} \mathrm{C}$ for one day. The liquid phase and hydrochars were weighed and stored in sealed containers until further analysis. Additionally, the liquid phase, so-called HTC water, was analysed by liquid chromatography method. The $\mathrm{pH}$ of all studied samples were also measured. The schematic of the hydrothermal carbonization and parameters of the process are summarized in the diagram (Figure 4).

Hydrochars were named as HTC_4, HTC_7, HTC_10, and HTC_12 according to carbonization times used during the process.

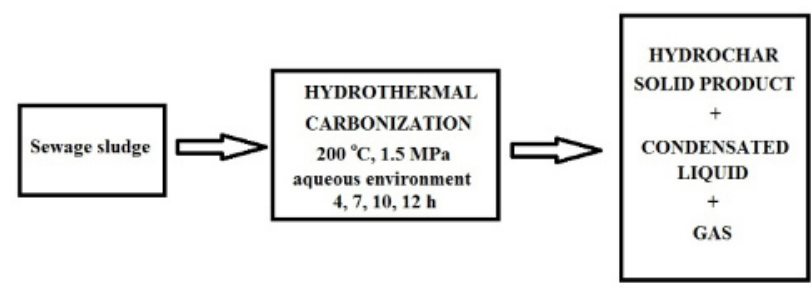

Figure 4. The HTC parameters. 


\subsection{Analytical methods}

The proximate analysis (moisture, ash, volatile matter, and fixed carbon) of the sewage sludge and hydrochars were determined according to European Standards. The moisture content was determined by maintaining $1 \mathrm{~g}$ of the samples in the drying system at $105^{\circ} \mathrm{C}$ to a constant mass according to EN 15934:2012. The ash content was determined by burning a $1 \mathrm{~g}$ sample of all studied solid recovered fuels in a muffle furnace at $600+/-10^{\circ} \mathrm{C}$ for $6 \mathrm{~h}$ according to PN-EN 14775:2010. The volatile matter was determined by maintaining the $1 \mathrm{~g}$ of mass samples at $900+/-10^{\circ} \mathrm{C}$ for 7 min using the EN 15402:2011 method. The fixed carbon content was determined by the difference:

$$
F C=100-A s h-V M-M, \%
$$

where: FC (\%), Ash (\%), VM (\%), and $\mathrm{M}(\%)$, respectively, indicate the mass percentages of fixed carbon, ash, volatile matter and moisture.

The ultimate analysis (carbon, hydrogen and nitrogen content) were measured by Elemental Analyser Truespec CHN Leco. The LECO CHN628 is a combustion elemental $\mathrm{C}, \mathrm{H}$, and $\mathrm{N}$ instrument that utilizes only pure oxygen in a furnace, ensuring complete combustion and superior recovery of the elements of interest. An Analyser CHS580 ELTRA was used to determine the sulphur content. The analyser is designed to determine both carbon and sulphur content in a wide variety of organic materials as well as some inorganic materials by combustion with non-dispersive infrared detection.

The higher heating value of the samples was calculated according to the Channiwala and Parikh correlation based on elemental composition:

$$
H H V=0.349 \cdot \mathrm{C}+1.1783 \cdot \mathrm{H}+0.10055 \cdot \mathrm{S}-0.1034 \cdot \mathrm{O}-
$$

In order to determine the combustion process of sewage sludge and hydrochar thermogravimetric analysis was conducted by the use of Netzsch STA 449 F3 Jupiter. The advantages of thermogravimetric analysis include its rapid assessment of the fuel value, the temperatures at which combustion starts and ends, and other characteristics such as maximum reactivity temperature, ash amount and total combustion time. Therefore, this technique is very useful for describing the combustion processes of fuels of different origin $[20,21]$. The hydrothermal conversion of sewage sludge and hydrochars were tested under a temperature regime in air atmospheres. The samples were heated in alumina crucibles from an ambient temperature up to $1200^{\circ} \mathrm{C}$ at a constant rate of $10^{\circ} \mathrm{C} / \mathrm{min}$ and at a $40 \mathrm{ml} / \mathrm{min}$ flow of air. The results were presented in the form of TG, DTG, and DSC curves, respectively. Thermogravimetry (TG) presents the weight loss of studied samples in contrast to the initial mass under an increasing temperature. Differential thermogravimetry (DTG) is based on the rate of weight loss. The peak temperature on DTG is the point where the rate of weight loss is at its maximum. Differential scanning calorimetry (DSC) additionally allows for the determination of thermal effects (endothermic and exothermic). The TG, DTG and DSC curves were used in order to assess the thermal characteristics of the studied samples.

\section{Results}

The proximate and ultimate analyses, fuel and atomic ratio, and HHV (higher heating values) of dried sewage sludge and hydrochars are presented in Table 1.

Table 1. Properties of sewage sludge and hydrochars.

\begin{tabular}{|c|c|c|c|c|c|}
\hline & SS & HTC_4 & HTC_7 & HTC_10 & HTC_12 \\
\hline FC,\% & 1.07 & 8.48 & 8.1 & 6.29 & 6.59 \\
\hline $\mathbf{V M , \%}$ & 55.11 & 39.27 & 38.00 & 40.17 & 39.34 \\
\hline Ash,\% & 34.29 & 49.47 & 52.8 & 52.84 & 53.08 \\
\hline $\mathbf{M , \%}$ & 10 & 2.78 & 1.1 & 0.7 & 1.00 \\
\hline FC/VM & 0.02 & 0.22 & 0.21 & 0.16 & 0.17 \\
\hline $\mathbf{C , \%}$ & 32.1 & 32.1 & 32.2 & 33.8 & 33.0 \\
\hline $\mathbf{H , \%}$ & 5.26 & 3.93 & 3.68 & 3.8 & 3.72 \\
\hline $\mathbf{N , \%}$ & 4.7 & 2.7 & 2.57 & 2.8 & 2.56 \\
\hline $\mathbf{S , \%}$ & 1.56 & 1.29 & 1.15 & 1.33 & 1.00 \\
\hline $\mathbf{O} \mathbf{a}, \%$ & 23.64 & 10.51 & 7.60 & 5.43 & 6.64 \\
\hline $\mathbf{H / C}$ & 1.97 & 1.47 & 1.37 & 1.35 & 1.35 \\
\hline $\mathbf{O} / \mathbf{C}$ & 0.52 & 0.25 & 0.18 & 0.12 & 0.15 \\
\hline $\begin{array}{c}\text { HHV, } \\
\mathbf{M J / k g}\end{array}$ & 14.42 & 13.83 & 13.79 & 14.73 & 14.19 \\
\hline
\end{tabular}

a - calculated by difference

By analysing the properties of hydrochars, the most evident changes are observed based on the fixed carbon. The fixed carbon, resulting from hydrothermal carbonization ranges from $8.48 \%$ to $6.59 \%$, compared with that of the dried sewage sludge - 1.07. The highest FC value are obtained for $4 \mathrm{~h}$ of carbonization time, then with an increase of reaction time the FC decreases, but still has c.a. seven times higher values. High FC is obtained, because the volatile matter (VM) of the chemical dehydration and decarboxylation reactions. The VM content for sludge is $55.11 \%$, whereas for hydrochars it seems to be at a similar level, approximately $39.2 \%$, and the carbonization time does not affect it. Furthermore, the fuel ratio (FC/VM) increases from 0.02 to 0.22 for $4 \mathrm{~h}$ of time used and decreases to 0.17 with increasing HTC time. Additionally, the ash content increases from $34.29 \%$ to 53.08 , following carbonization due to excess loss of VM caused by HTC reactions, and rises as time is increased. The ash content is significantly higher compared to the initial SS. Sewage sludge ash deposition is a significant problem in the energy industry sector. The formation and transformation of sewage sludge ash stimulates the corrosion processes by slagging and fouling [22]. The hydrothermal carbonization enhances the ash content of hydrochar when the reaction time is increased. Therefore, it suggests that in this case $4 \mathrm{~h}$ of carbonization time is enough to obtain good thermal properties of hydrochar.

HTC brings about changes to the elemental compositions of dried sewage sludge caused by different carbonization times. Carbon content slightly increases, 
but a decrease in hydrogen, nitrogen, and sulphur has been observed when reaction time has been increased, except for carbonization at $10 \mathrm{~h}$. The sulphur content significantly decreases from 1.56 to 1.0 , whereas the nitrogen content decreases from 4.7 to 2.56 (Figure 5). Therefore, the observed $35 \%$ reduction of sulphur and $45 \%$ in the case of nitrogen content caused by the HTC process, positively eliminates the potential risk of generating harmful pollutants such as $\mathrm{NO}_{\mathrm{x}}$ and $\mathrm{SO}_{\mathrm{x}}$. During HTC process volatile-N converted to the gas and liquid. It is confirmed by the liquid chromatography detecting a significant rank of heterocyclic compounds contains -N. Finally, the chemical composition of the investigated hydrochars confirms their relevant properties for the combustion process.

The HHVs are calculated taking into account the elemental composition and are low, around $14 \pm 15$ $\mathrm{MJ} / \mathrm{kg}$, compared to lignite. The HTC process has a low impact on the hydrochar HHV, and for HTC_10 h the HHV has slightly increased to $14.73 \mathrm{MJ} / \mathrm{kg}$.

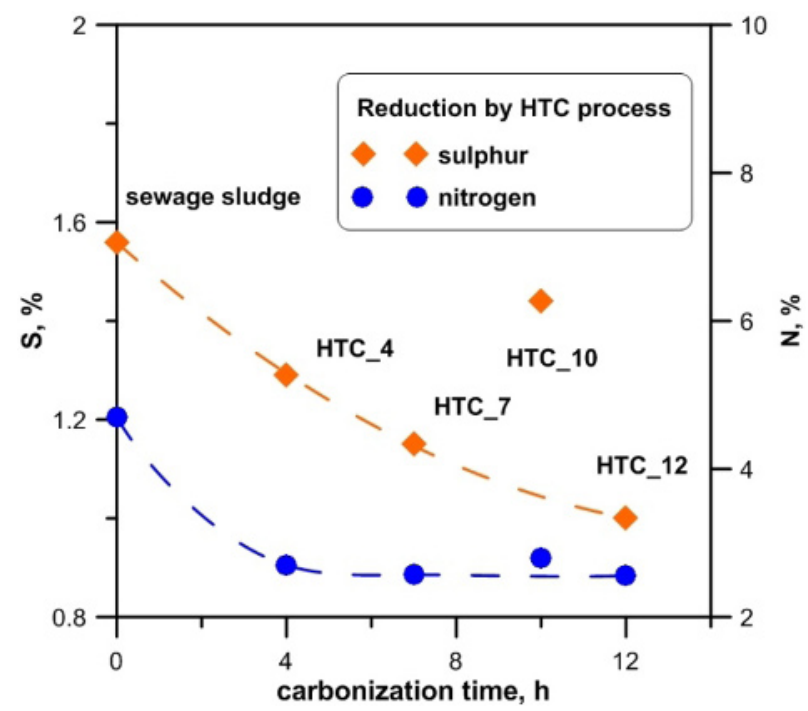

Figure 5. The effect of carbonization time on sulphur and nitrogen reduction under HTC process.

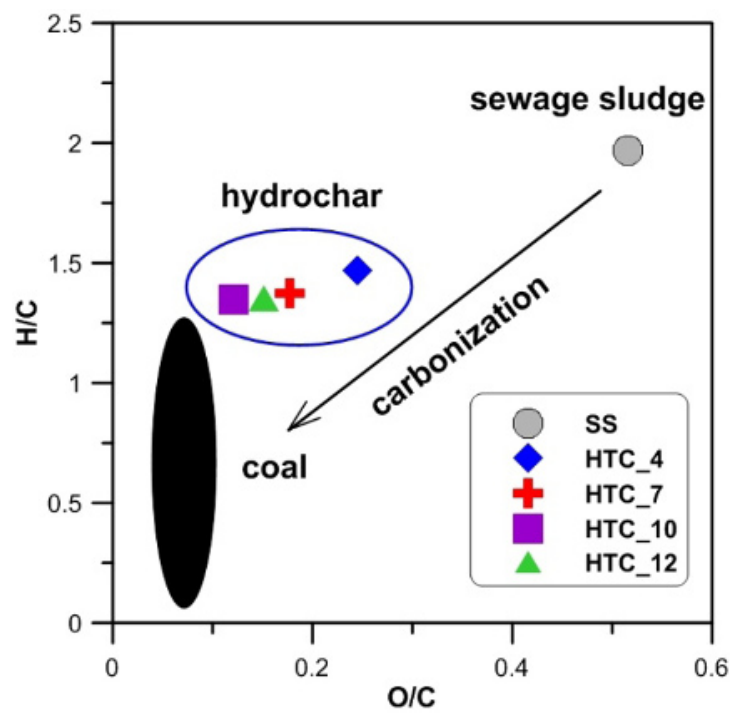

Figure 6. Van Krevelen diagram of sewage sludge and hydrochars.
In order to investigate the difference in the atomic composition of SS and hydrochars, $\mathrm{H} / \mathrm{C}$ and $\mathrm{O} / \mathrm{C}$ atomic ratios are depicted in the van Krevelen diagram (Figure 6). As can be clearly seen hydrothermal carbonization led to a decrease in $\mathrm{H} / \mathrm{C}$ and $\mathrm{O} / \mathrm{C}$ atomic ratios for all studied char samples. For comparison, the $\mathrm{H} / \mathrm{C}$ and $\mathrm{O} / \mathrm{C}$ rations for coal are also plotted. As shown in Figure 2 the atomic ratio of $\mathrm{H} / \mathrm{C}$ and $\mathrm{O} / \mathrm{C}$ reduces at a different degree after carbonization, from 1.92 and 0.52 to 1.35 and 0.15 , respectively. In this regard, the reduced ratios confirms the significant effect of the HTC method in enhancing the fuel properties of hydrochars. Therefore, HTC can produce a renewable fuel with properties more like coal.

In order to study the thermal behaviour of raw and HTC sewage sludge during combustion, thermal analysis was used. The thermogravimetric studies of sewage sludge and hydrochar are presented in TG, DTG, and DSC curves. The various hydrochar samples obtained under $200^{\circ} \mathrm{C}$ and $12 \mathrm{~h}$ of HTC process were chosen as an example of HTC products. Combustion profiles of the samples are plotted in Figure 7 and 8.

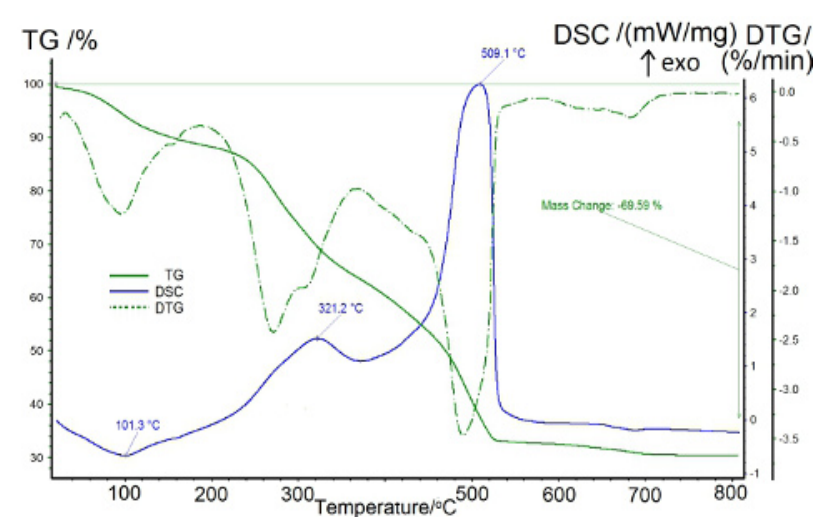

Figure 7. TG, DTG and DSC profiles for sewage sludge.

The sewage sludge combustion profiles differ for both studied samples. The sewage sludge combustion process takes place in three stages: the initial stages of decomposition, main decomposition and final decomposition. The first stage, corresponding to the moisture content, takes place up to c.a. $200^{\circ} \mathrm{C}$. The mass loss is $10 \%$. The main decomposition during the combustion process is in the $200-550^{\circ} \mathrm{C}$ temperature range. The second stage shows the presence of two main effects. Two maximum weight loss rates (DTG curves) occur at $270^{\circ} \mathrm{C}$ and $490^{\circ} \mathrm{C}$, therefore two exothermic effects are observed $\left(321^{\circ} \mathrm{C}\right.$ and $\left.509^{\circ} \mathrm{C}\right)$ connected with oxidation of organic matter. Mass loss after the main stage is $66 \%$. Above $550^{\circ} \mathrm{C}$ there is no significant mass change. It can be assumed that above $700^{\circ} \mathrm{C}$ the combustion process is finished and the ash content is c.a. $30 \%$. Based on TGA results the hydrothermal carbonization process causes evident changes in the thermal decomposition of sewage sludge. It was confirmed that the HTC product has insignificant moisture content, the peak connected with moisture loss does not appear. In the main stage $\left(240-500^{\circ} \mathrm{C}\right)$ four exothermic effects are observed with the main effects at temperatures of $262^{\circ} \mathrm{C}$ and $358^{\circ} \mathrm{C}$. For the HTC product the combustion process concludes at a lower temperature than raw sewage sludge. However, the final mass change is not observed above $720^{\circ} \mathrm{C}$. 
Despite that fact, combustion of hydrochar takes place within a narrower range of temperatures as the ash content is evidently higher, which can be an operating problem during HTC product combustion. The characteristic parameters obtained from TG, DTG, and DSC profiles of studied fuels are summarized in Table 2 .

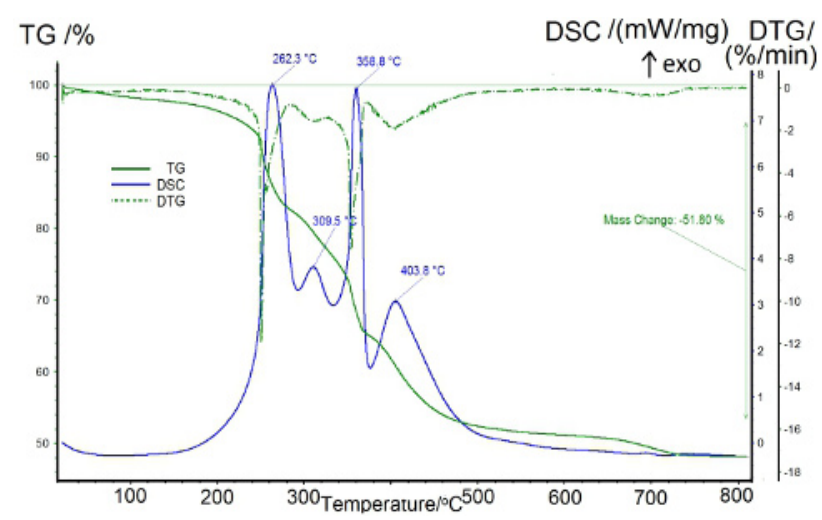

Figure 8. TG, DTG and DSC profiles for hydrochar HTC_12.

Additionally, the $\mathrm{pH}$ value of liquid phase which was generated from HTC under 4, 7, 10, and $12 \mathrm{~h}$ of carbonisation was measured after the process and was at a similar level, approximately 7 .

Table 2. Characteristic parameters obtained from DTG profiles of studied fuels during the combustion process. $T_{m}$, temperature of the maximum weight loss rate; $\mathrm{DTG}_{\max } ; \mathrm{m}$, maximum weight loss rate; $\mathrm{m}_{\mathrm{A}}$, solid residue.

\begin{tabular}{|c|c|c|c|}
\hline $\mathbf{T}_{\mathbf{m}},{ }^{\circ} \mathbf{C}$ & $\begin{array}{c}\text { DTG } \\
\mathbf{\%} / \mathbf{m i n}\end{array}$ & $\mathbf{m}, \mathbf{\%}$ & $\mathbf{m}_{\mathbf{A}}, \mathbf{\%}$ \\
\hline \multicolumn{5}{|c|}{$\mathbf{S S}$} \\
\hline 101 & 1.25 & 5.7 & \\
\hline 321 & 1.8 & 38 & \\
\hline 490 & 3.4 & 57 & 30 \\
\hline 800 & - & 70 & \\
\hline \multicolumn{5}{|c|}{ HTC_12 } \\
\hline 250 & 11.8 & 8 & \\
\hline 350 & 7.5 & 23 & 48 \\
\hline 800 & - & 52 & \\
\hline
\end{tabular}

\section{Conclusions}

According to the hydrothermal carbonization investigation of sewage sludge, the process can be named as a promising technology which enhances the thermal properties of raw material. The results confirm that the properties of hydrochars moved from sewage sludge towards coal (higher fixed carbon content and fuel ratio, improved chemical composition). Taking into account the impact of carbonization time on the samples it can be concluded that $4 \mathrm{~h}$ of carbonization time is quite enough to obtain good thermal properties of hydrochar. Furthermore, the thermogravimetric analysis confirms the different thermal behaviour of hydrochars for the combustion process. Finally, the HTC process can be used as a novel and alternative method to convert wet sewage sludge into dry solid biofuel.

\section{Acknowledgement}

The work was supportedby grant AGH no. 11.11.110.423.
The Author is grateful to EKOPROD Ltd. the proprietor of the HTC apparatus used in the presented study.

\section{References}

1. A. Magdziarz, S. Werle., Waste Manag., 34, 174 (2014)

2. M. Wilk, A. Magdziarz, I. Kalemba, Energy, 87, 259 (2015)

3. B. Kosturkiewicz, A. Magdziarz, M. Wilk, Rynek Energii, 5, 111 (2011)

4. A. Funke, F. Ziegler, Bioresour. Technol., 102, 7595 (2011)

5. S. Roman, J. M. V. Nabais, C. Laginhas, B. Leesma, J. F. Gonzales, Fuel Proc. Technol., 103, 78 (2012)

6. J. Stemann, A. Putschew, F. Ziegler, Bioresour. Technol., 143, 139 (2013)

7. M. Pala, I. C. Kantarli, H. B. Buyukisik, J. Yanik, Bioresour. Technol., 161, 255 (2014)

8. M. T. Reza, J. Mumme, A. Ebert, Biomass Conv. Bioref. 5, 425 (2015)

9. G. K. Parshetti, S. K. Hoekman, R. Balasubramanian, Bioresour. Technol., 135, 683 (2013)

10. I. Oliveira, D. Blohse, H.-G. Ramke, Bioresour. Technol., 142, 138 (2013)

11. S. Kang, X. Li, J. Fan, J. Chang, Ind. Eng. Chem. Res., 51, 9023 (2012)

12. C. Peng, Y. Zhai, Y. Zhu, B. Xu, T. W., C. Li, G. Zeng, Fuel, 176, 110 (2016)

13. C. He, J. Zhao, Y. Yang, J.-Y. Wang, Bioresour. Technol., 211, 486 (2016)

14. K. Fakkaew, T. Koottatep, C. Polprasert, Bioresour. Technol., 192, 328 (2015)

15. E. Danso-Boateng, R.G. Holdich, G. Shama, A.D. Wheatley, M. Sohail, S. J. Martin, App. Energy, 111, 351 (2013)

16. D. Kim, K. Lee, K. Y. Park, Fuel, 130, 120 (2014)

17. P. Zhao, Y. Shen, S. Ge, K. Yoshikawa, Energy Conv. Manag., 78, 815 (2014)

18. C. He, A. G., J. Y. Wang, App. Energy, 111, 257 (2013)

19. J. Zhang, Q. Lin, X. Zhao, J. Inter. Agric., 13, 3, 471 (2014)

20. A. Magdziarz, M. Wilk, J. Therm. Anal. Calorim., 114, 2, 519 (2013)

21. A. Magdziarz, M. Wilk, Energy Conv. Manag., 75, 425 (2013)

22. A. Magdziarz, A. K. Dalai, J. A. Koziński, Fuel, 176, 135 (2016). 